\title{
A comparison of lumbar epidural and intravenous fentanyl infusions for post- thoracotomy analgesia
}

This double-blind randomised study compared the analgesic efficacy, respiratory effects, side effects, and pharmacokinetic disposition of $24 \mathrm{hr}$ lumbar epidural and intravenous infusions of the same dosage regimen of fentanyl $\left(1.5 \mu \mathrm{g} \cdot \mathrm{kg}^{-1}\right.$ bolus then $1 \mu \mathrm{g} \cdot \mathrm{kg}^{-1} \cdot \mathrm{hr}^{-1}$ infusion) in 50 patients after thoracotomy. Patients received either epidural fentanyl and intravenous normal saline, or epidural normal saline and intravenous fentanyl, for postoperative analgesia, after a standard low-dose alfentanil and isoflurane general anaesthetic. Visual analogue pain scores were lower in the epidural group $(P<0.05)$ only at two hours postoperatively, and there was no difference in the amount of supplementary morphine self-administered by patient-controlled analgesic pump. A mainly spinal analgesic effect probably occurred in the first few hours since fentanyl was not detectable in the plasma of patients in the epidural group until two hours afier bolus injection; its concentration was less at that time than afier intravenous injection $(P<$ 0.05 ). Thereafter there was no difference in the plasma concentration profiles between the two groups. Seven patients in the epidural group and ten patients in the intravenous group received naloxone for $\mathrm{PaCO}_{2}>50 \mathrm{mmHg}$, and one patient in the intravenous group had the infusions stopped because of $\mathrm{PaCO}_{2}$ elevation and somnolence. In patients who did not receive naloxone, the epidural route produced better analgesia throughout the study period $(P<0.01)$. Indices of respiratory

\section{Key words}

ANALGESIA: postoperative;

ANALGESICS: fentanyl;

ANAESTHETIC TECHNIQUES: epidural, lumbar.

From the Department of Anaesthesia, Ottawa General

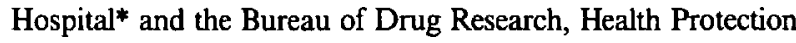
Branch, Tunney's Pasture, Ottawa. $\dagger$

Address correspondence to: Dr. Alan D. Baxter, Department of Anaesthesia, Ottawa General Hospital, Smyth Road,

Ottawa, Ontario K1H 8L6.

Presented, in part, at the CAS Annual meeting, Halifax, 1993.

Accepted for publication 24th November, 1993.
Alan D. Baxter BM BS FRCPC FRCA,*

Sylvie Laganière PhD, $†$ Benoit Samson MD FRCPC,*

John Stewart MD FRCPC, * Kathryn Hull RN,

Lynne Goernert RT $\dagger$ centre function (apnoeas $>15 \mathrm{sec}$, slow respiratory rate $<10$ min $^{-1}$, oxyhaemoglobin desaturation $<90 \%$ and $\mathrm{PaCO}_{2}$ ) spirometric measures of pulmonary function, haemodynamic variables, morbidity, and other side effects, were similar in both groups, irrespective of naloxone therapy. Patients who had no respiratory depression and did not require naloxone had better analgesia with epidural fentanyl. However, this advantage did not result in better pulmonary function.

Cette étude randomisée et à double aveugle compare pendant $24 \mathrm{~h}$ l'efficacité analgésique, les effets respiratoires, les effets secondaires et la disposition pharmacocinétique diune épidurale lombaire avec la perfusion iv de doses identiques de fentanyl (bolus de $1,5 \mu \mathrm{g} \cdot \mathrm{kg}^{-1}$ suivi diune perfusion de 1 $\mu \mathrm{g} \cdot \mathrm{kg}^{-1} \cdot \mathrm{h}^{-1}$ ) chez 50 thoracotomisés. Après une anesthésie standardisée à l'soflurane avec de faibles doses de sufentanil, les patients reçoivent pour l'analgésie postopératoire soit du fentanyl épidural et du soluté physiologique iv, soit du soluté physiologique épidural et du fentanyl iv. Les scores de l'échelle visuelle analogue sont inférieurs pour le groupe épidural $(P<$ $0,05)$ seulement à la deuxième heure postopératoire. Il n'y a pas de différence pour la quantité de morphine supplémentaire auto-administrée par pousse-seringue. Selon toute probabilité, l'effet analgésique des premières heures est surtout d'origine rachidienne étant donné que le fentanyl ne peut être détecté dans le plasma des patients du groupe épidural qu'après deux heures de linjection en bolus: à ce moment, sa concentration est inférieure à celle qui suit linjection intraveineuse $(P<0,05)$. Par la suite, on ne détecte pas de différence de concentrations plasmatiques entre les deux groupes. Sept patients du groupe épidural et dix patients du groupe intraveineux ont reçu du naloxone parce que la $\mathrm{PaCO}_{2}$ était plus élevée que $50 \mathrm{mmHg}$. et chez un patient du groupe intraveineux on a dû arrêter la perfusion à cause de l'augmentation de la $\mathrm{PaCO}_{2}$ et la somnolence. Chez les patients qui n'ont pas reçu de naloxone, la voie épidurale produit une meilleure analgésie $(P<0,01)$. Les indices de la fonction du centre respiratoire (apnée $>15 \mathrm{sec}$, fréquence respiratoire $<10 \mathrm{~min}^{-1}$, désaturation $<90 \%$ et $\mathrm{PaCO}_{2}$ élevée), la spirométrie, les variables hémodynamiques, la morbidité et les effets secondaires sont les mêmes dans les 
deux groupes, indépendamment du traitement à la naloxone. Lanalgésie est supérieure chez les patients sans dépression respiratoire et sans naloxone. Cependant cette supériorité ne signifie pas une meilleure fonction respiratoire.

Many studies have documented the efficacy of epidural opioid analgesia for pain relief and prophylaxis of pulmonary morbidity after major abdominal and thoracic surgery. ${ }^{1-4}$ Since the early reports of the use of morphine by this route, other opioids have been evaluated, and fentanyl is enjoying current popularity as respiratory depression $^{5-8}$ and other side effects may be less than with epidural morphine. ${ }^{9,10}$ The efficacy of epidural fentanyl using both lumbar and thoracic catheter sites $5,11,12$ has been documented. Fentanyl ${ }^{13}$ is more lipophylic than morphine, ${ }^{14}$ and this is probably why there is relatively less respiratory depression, as less of the drug should remain in the cerebrospinal fluid for cephalad migration.

Because of its short duration ${ }^{5}$ of action epidural fentanyl is administered by continuous infusion. After epidural injection, there is rapid uptake of fentanyl into epidural blood vessels as well as into the spinal cord, and blood concentrations obtained after lumbar epidural infusion $^{8,12,15-17}$ have often been in the range reported as being effective analgesic blood concentrations with systemic infusions. ${ }^{18-20}$ Recent studies have questioned whether the analgesic efficacy of epidural fentanyl is secondary to systemic absorption and recirculation to the central nervous system through the blood-brain barrier, ${ }^{12,15,16,23}$ or is mediated by a direct spinal mechanism. ${ }^{25}$ If the former were the case, then there may be no advantage to the epidural route.

This study compared the analgesic efficacy, respiratory effects, side effects, and pharmacokinetic disposition of lumbar epidural and intravenous infusions of fentanyl using the same dosage regimen in patients after thoracotomy, to determine whether the more invasive epidural route is more advantageous than simple intravenous infusion.

\footnotetext{
Methods

After Human Experimentation Committee approval and with written informed consent, 50 ASA physical status I-III patients undergoing elective thoracotomy were studied in a double-blind fashion. Patients were assigned randomly with a computer-generated table to receive either epidural fentanyl and intravenous normal saline (Group 1), or epidural normal saline and intravenous fentanyl (Group 2), for postoperative analgesia. Exclusion criteria included age $<18$ or $>70 \mathrm{yr}$, body mass index $>30$, angina class $3-4$, severe respiratory dysfunction $\left(\mathrm{PaCO}_{2}\right.$ $>45 \mathrm{mmHg}$ and $\mathrm{PaO}_{2}<60 \mathrm{mmHg}$ breathing room
}

air, $\mathrm{FEV}_{1}<1.2 \mathrm{~L}$ ), communication problems, chronic opioid use, and abnormal renal or hepatic function.

\section{Anaesthesia}

In addition to routine preoperative investigations, pulmonary function studies included $F E V_{1}$, forced vital capacity (FVC), peak expiratory flow rate (PEFR), maximal inspiratory pressure (MIP), maximal expiratory pressure (MEP), and arterial blood gas analysis. Routine intraoperative monitoring for thoracic surgery was used. Preoperatively patients were instructed in the use of the $0-10$ visual analogue scale (VAS) for pain assessment and the patient controlled analgesia (PCA) pump for supplementary analgesia.

Patients received diazepam $0.1 \mathrm{mg} \cdot \mathrm{kg}^{-1}$ po approximately one hour preoperatively. A lumbar epidural catheter was inserted at $\mathrm{L}_{2-3}$ or $\mathrm{L}_{3-4}$, and a total of eight millilitres of $2 \% \mathrm{CO}_{2}$ lidocaine with epinephrine $1: 200,000$ was injected to confirm epidural location by the onset of appropriate sensory changes. Anaesthesia was induced with thiopentone $3-5 \mathrm{mg} \cdot \mathrm{kg}^{-1}$ and alfentanil 10 $\mu \mathrm{g} \cdot \mathrm{kg}^{-1}$. Muscle relaxation was achieved with vecuronium $0.1 \mathrm{mg} \cdot \mathrm{kg}^{-1}$. Routine airway and ventilatory management were used as appropriate for the type of surgery. Anaesthesia was maintained with nitrous oxide, oxygen, isoflurane, vecuronium, and alfentanil (total dose for the operation including induction dose up to 20 $\mu \mathrm{g} \cdot \mathrm{kg}^{-1}$ ) as required. Intercostal blocks were performed after induction of anaesthesia and before surgery with $2 \% \mathrm{CO}_{2}$ lidocaine with 1:200,000 epinephrine on four intercostal nerves at the level of the surgical incision to reduce requirements for general anaesthetic agents. Neuromuscular blockade was reversed with edrophonium and atropine, and the patients' tracheas were extubated within two hours from the end of surgery.

\section{Treatment}

After resumption of spontaneous respiration, and prior to extubation, patients in Group 1 received an epidural bolus of $1.5 \mu \mathrm{g} \cdot \mathrm{kg}^{-1}$ fentanyl in saline, $10 \mu \mathrm{g} \cdot \mathrm{ml}^{-1}$, in four divided doses over $15 \mathrm{~min}$, followed $30 \mathrm{~min}$ later on arrival in the recovery room by an infusion of 1 $\mu \mathrm{g} \cdot \mathrm{kg}^{-1} \cdot \mathrm{hr}^{-1}$ fentanyl epidurally for $24 \mathrm{hr}$. At the same time, an equal volume of saline was injected $\dot{i}$ followed by a saline infusion for $24 \mathrm{hr}$. Patients in Group 2 received an $i v$ bolus of $1.5 \mu \mathrm{g} \cdot \mathrm{kg}^{-1}$ fentanyl in saline, 10 $\mu \mathrm{g} \cdot \mathrm{ml}^{-1}$, in four divided doses over $15 \mathrm{~min}$ (to avoid apnoea and maintain blinding), followed by an infusion of $1 \mu \mathrm{g} \cdot \mathrm{kg}^{-1} \cdot \mathrm{hr}^{-1}$ fentanyl $i v$ for $24 \mathrm{hr}$. At the same time, an equal volume of saline was injected epidurally followed by a saline infusion for $24 \mathrm{hr}$. Both intravenous and epidural solutions were prepared by the hospital pharmacy and provided to the investigators in vials labelled only with the patient's name and study number. 
In the Recovery Room, oxygen was administered to maintain $\mathrm{SaO}_{2}>90 \%$, and $\dot{i}$ fluids were infused as clinically indicated. All patients were provided with a PCA pump with which they could administer one milligram increments of morphine $i v$ on demand, with a five-minute lockout interval, in order to ensure maximum patient comfort. Vital signs were recorded as usual, and the patients were kept in the recovery room for $24 \mathrm{hr}$ as part of routine post-thoracotomy care.

If the $\mathrm{PaCO}_{2}$ was elevated above $50 \mathrm{mmHg}$ two or more hours after emergence from anaesthesia, then naloxone $1 \mu \mathrm{g} \cdot \mathrm{kg}^{-1}$ was injected $i v$, followed by an infusion of $1 \mu \mathrm{g} \cdot \mathrm{kg}^{-1} \cdot \mathrm{hr}^{-1}$. Further naloxone treatment was according to the patient's clinical condition or arterial blood gas analysis.

\section{Measurements}

Data collection was by nursing staff experienced in the use of the various scales and supervised by a research assistant, and unaware of the patients' study group:

1 Analgesia - pain intensity was recorded by the patient by VAS on arrival in the recovery room and two hourly thereafter. Self-administered $i v$ morphine requirements were noted for the first $24 \mathrm{hr}$.

2 Respiratory function - arterial blood gases were measured two hourly, and FEV, FVC, MIP, MEP, PEFR performed at six, 12, and $24 \mathrm{hr}$. Respiratory inductive plethysmography (Vitalog) and pulse oximetry were begun in the recovery room as soon as the patient was able to cooperate with calibration, using a technique previously described, ${ }^{21}$ and the respiratory pattern (respiratory rate, tidal volume, apnoeas $>15 \mathrm{sec}$, episodes of bradypnoea $<10 \mathrm{~min}^{-1}>5 \mathrm{~min}$, and episodes of desaturation $>90 \%$ ) studied for $24 \mathrm{hr}$.

3 Side effects - occurrence of pruritus, nausea or vomiting was noted, and sedation was recorded using a 1-6 scale ${ }^{10}(1=$ mostly awake, $2=$ asleep and opens eyes to noise, $3=$ asleep and opens eyes to name, $4=$ asleep and opens eyes to physical stimulus, $5=$ asleep and moves and makes noise to physical stimulus, $6=$ unconscious and unarousable).

4 Five millilitre blood samples were drawn from the arterial line immediately before injection of the first epidural and intravenous boluses, and at 4, 9, 14, 30, 45 min, and 1, 2, 4, 6, 8, 10, 12, and $24 \mathrm{hr}$ after the initial injection. The infusions were stopped at $24 \mathrm{hr}$, and blood was collected at $3,6,9$, and $12 \mathrm{hr}$ afterwards. Blood was collected in polypropylene tubes containing EDTA, centrifuged for ten minutes and the plasma stored at $-20^{\circ} \mathrm{C}$ until analysis.

\section{Fentanyl assay}

Fentanyl was analyzed in plasma by gas chromatography
TABLE I Demographic data (mean \pm SD) - there were no differences between the two groups

\begin{tabular}{lll}
\hline & Epidural & Intravenous \\
\hline Male/female $(n)$ & $15 / 10$ & $14 / 11$ \\
Age (yr) & $60 \pm 8$ & $55 \pm 13$ \\
Weight $(\mathrm{kg})$ & $70.0 \pm 12$ & $70.0 \pm 10$ \\
Lobectomy/pneumonectomy/ & & \\
$\quad$ hiatus hernia/pleurectomy $(n)$ & $18 / 4 / 1 / 2$ & $19 / 4 / 1 / 1$ \\
Intraoperative alfentanil $(\mu \mathrm{g})$ & $1067 \pm 285$ & $1172 \pm 351$ \\
\hline
\end{tabular}

with nitrogen detection. ${ }^{22}$ The assay was validated over the range $0.25-3 \mathrm{ng} \cdot \mathrm{ml}^{-1}$ for intra- and inter-day precision and accuracy, and the stability of fentanyl plasma samples was assessed over time. The inter-day accuracy (defined as the mean percentage deviation from nominal value), and the mean coefficient of variation for precision obtained over a six-week period at $0.5,1.5$, and 3 $\mathrm{ng} \cdot \mathrm{ml}^{1}$, were respectively $-5.7,-2.5,3.3 \%$ and $5.7,7.3$, and $6.8 \%$. On each analytical day, a standard curve was run along with quality control samples. The low limit of quantitation of the method was $0.25 \mathrm{ng} \cdot \mathrm{ml}^{-1}$ using two millilitres of plasma.

\section{Data and statistical analysis}

The sample size calculation was based on the data of Gourlay. ${ }^{20}$ A sample size of 25 patients per group was required to detect a difference in fentanyl concentration of $0.2 \mathrm{ng} \cdot \mathrm{ml}^{-1}$ between groups with an alpha of 0.05 and power of at least 0.80 . Pain and sedation scores, supplementary morphine, and haemodynamic and respiratory variables were analysed using analysis of variance for repeated measures using the SAS program; Student's $t$ test for unpaired data or Chi-square was used to compare demographic and pharmacokinetic data, and differences in frequency of side effects between groups. Results were expressed as mean \pm standard deviation, and $P<0.05$ was considered significant.

\section{Results}

There were no demographic differences between the two groups (Table I) for sex distribution, age, weight, type of surgery, or alfentanil administration intraoperatively. There was no difference between the groups in the administration of medications such as salbutamol, calcium channel blocking drugs, theophylline, diuretics, histamine-2 antagonists, etc., which were used as clinically indicated.

\section{Analgesia}

There was no difference in VAS (analysis of variance for repeated measures) between the two groups (Figure 1 ), except two hours after surgery when the scores in 


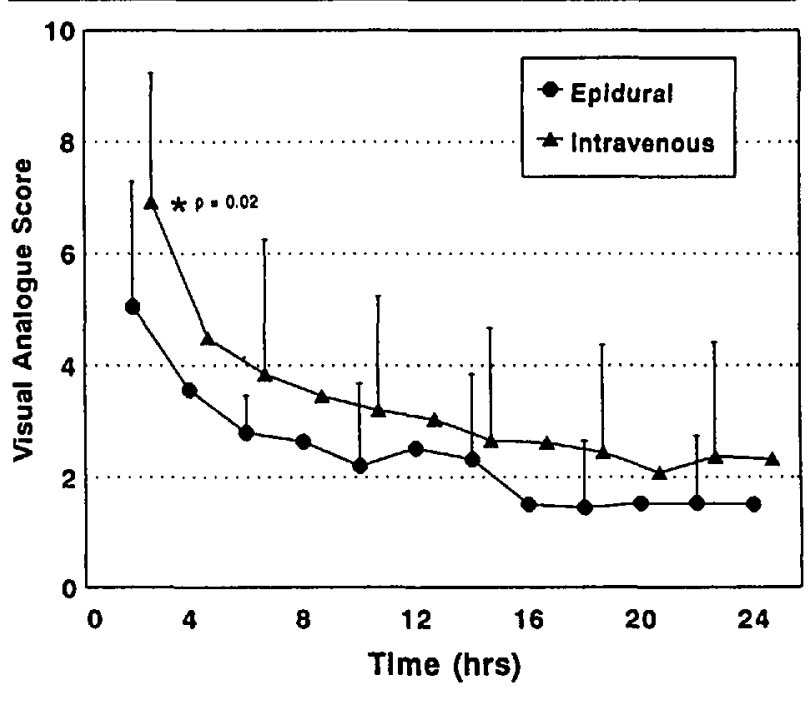

FIGURE 1 Visual analogue $(0-10)$ pain scores (mean $\pm S D$ ) were only different at two hours $(P=0.0175)$ for the groups overall. The trend towards lower pain scores in the epidural group became significant when only patients in both groups who did not require naloxone were considered $(P<0.01)$.

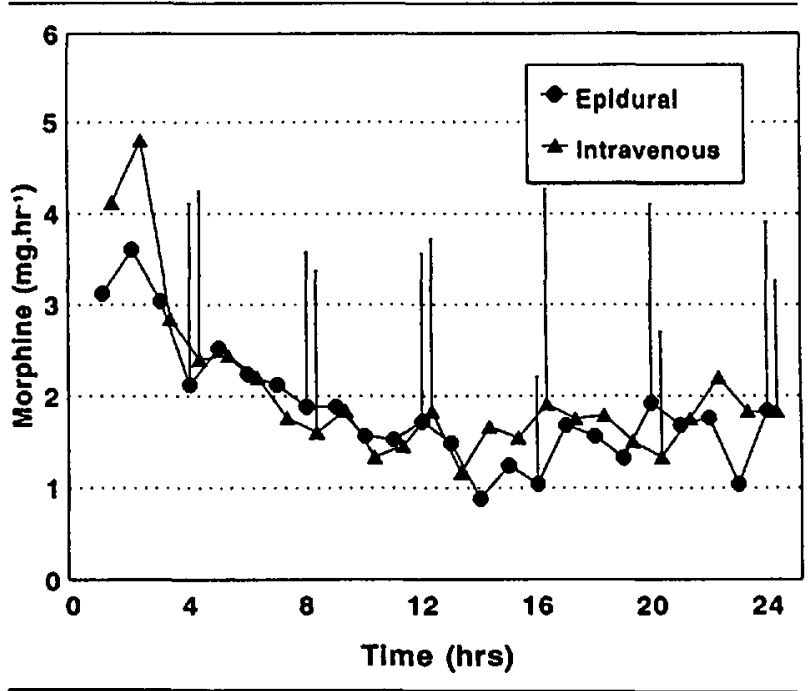

FIGURE 2 Morphine PCA supplementation (mean \pm SD) was similar in the two groups.

the epidural group were lower $(P<0.05)$. In this study, the power for detecting a difference of two in VAS scores was $93 \%$.

There was no difference in the amount of morphine self-administered by PCA (Figure 2), and the amount of additional morphine required varied considerably among patients with a coefficient of variation of $80-100 \%$. No patients were pain-free with the study drug alone, and all required PCA supplementation.
TABLE II Indices of respiratory centre function (episodes $\cdot$ hour $^{-1}$, mean $\pm S D$ ) were similar in the two groups

\begin{tabular}{lll}
\hline & Epidural & Intravenous \\
\hline Apnoeas $>15 \mathrm{sec}$ & $1.7 \pm 5.7$ & $1.0 \pm 2.8$ \\
$\mathrm{SaO}_{2}<90 \%$ & $1.1 \pm 1.1$ & $0.6 \pm 0.4$ \\
Respiratory rate $<10 \mathrm{~min}^{-1}$ & $0.7 \pm 1.0$ & $1.1 \pm 1.4$ \\
\hline
\end{tabular}

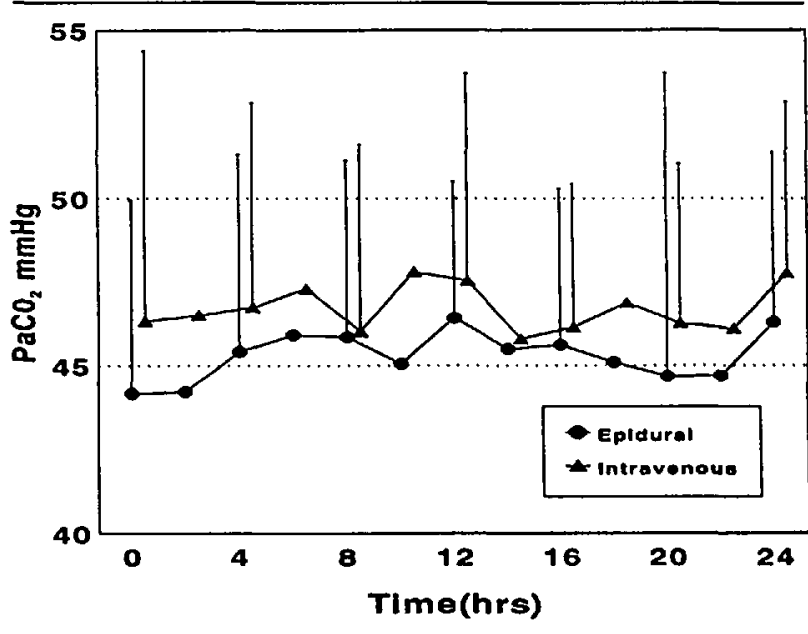

FIGURE $3 \mathrm{PaCO}_{2}$ (mean $\pm \mathrm{SD}$ ) was similar in the two groups, partly as a result of naloxone administration if $\mathrm{PaCO}_{2}>50 \mathrm{mmHg}$.

Within each group, there was no difference in PCA use between those who received naloxone and those who did not. However, VAS were lower at all times in the epidural group than in the intravenous group in those patients who did not receive naloxone $(P<0.01)$ for $\mathrm{PaCO}_{2}$ elevation. As only seven of 25 patients in the epidural group received naloxone, this represents an advantage to the epidural technique.

\section{Respiratory function}

Indices of respiratory centre function (Table II) were similar in the two groups. The $\mathrm{PaCO}_{2}$ measurements (Figure 3) were similar in the two groups, but this was influenced by the study design as naloxone was infused to reduce the $\mathrm{PaCO}_{2}$ if it exceeded a threshold of $50 \mathrm{mmHg}$. The requirement for naloxone was similar in the two groups (Table III), and did not have any effect on pulmonary function, side effects, outcome, etc. All patients completed the study except one patient in the intravenous group who had the infusions stopped because of a $\mathrm{PaCO}_{2}$ of $64 \mathrm{mmHg}$ and somnolence unresponsive to naloxone. Indices of pulmonary function $\left(\mathrm{FEV}_{1}, \mathrm{FVC}, \mathrm{PEFR}, \mathrm{MIP}\right.$, MEP) showed a similar pattern of impairment in both groups (Figure 4). 
TABLE III Side effects - there was no difference in the incidence of side effects between the two groups

\begin{tabular}{|c|c|c|}
\hline & Epidural & Introvenous \\
\hline Pruritus (n) & 6 & 5 \\
\hline Nausea and vomiting $(n)$ & 10 & 8 \\
\hline $\mathrm{PaCO}_{2}>50 \mathrm{mmHg}(n)$ & 9 & 14 \\
\hline Naloxone $(n)$ & 7 & 10 \\
\hline
\end{tabular}

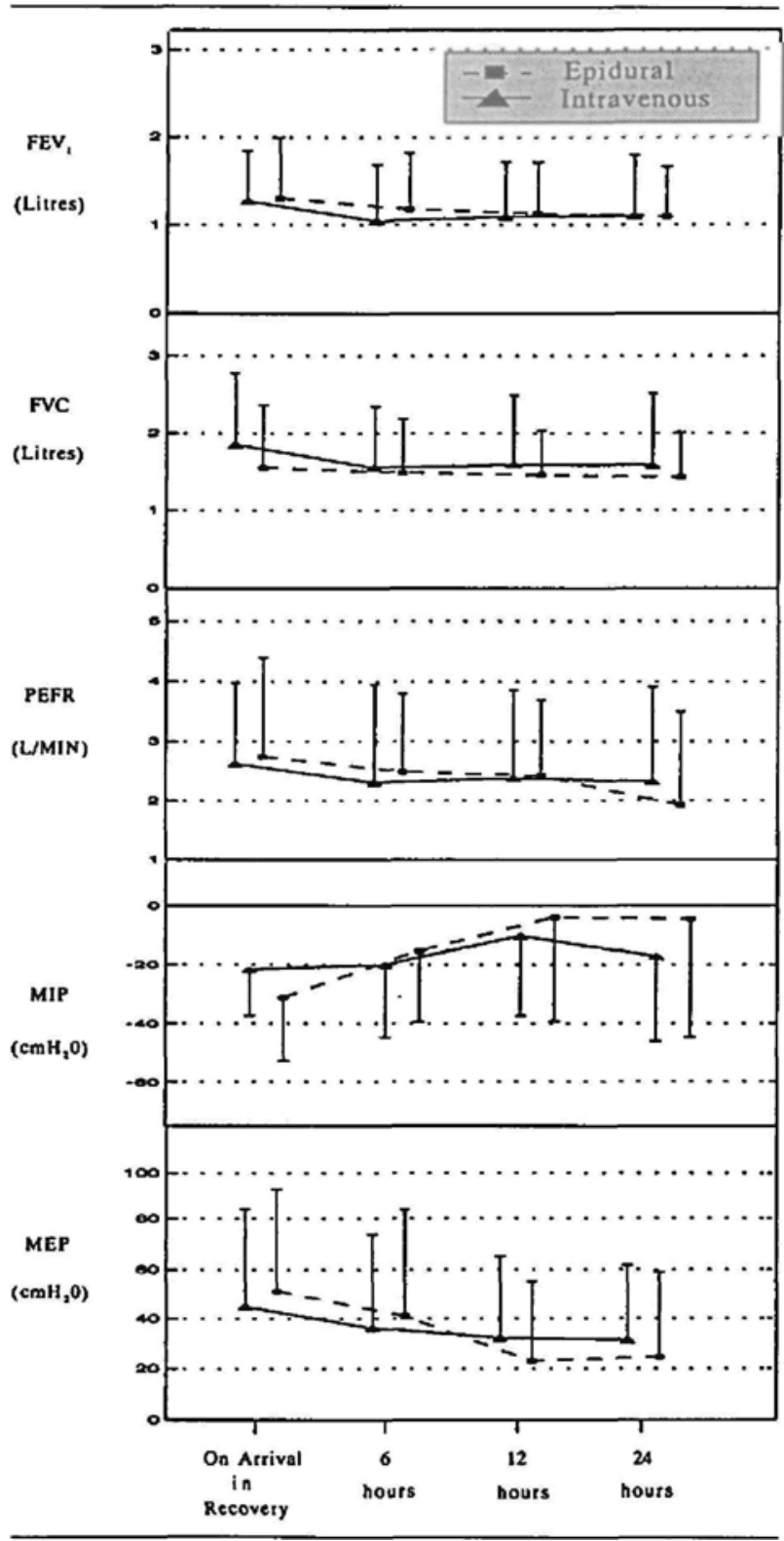

FIGURE 4 Spirometric pulmonary function tests (mean \pm SD) revealed a similar pattern of impairment in the two groups.

\section{Haemodynamics}

Systolic blood pressure (Figure 5) and heart rate measurements were similar in the two groups.

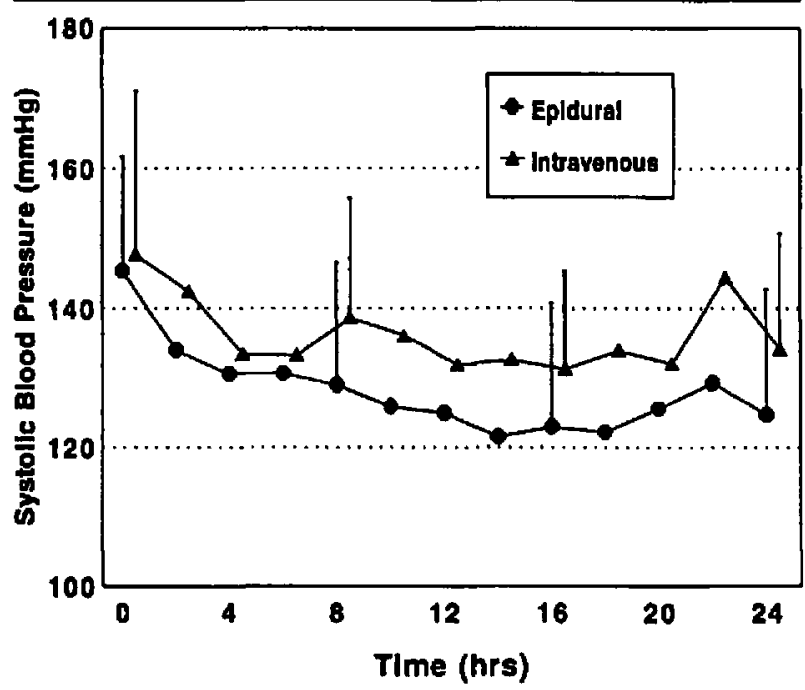

FIGURE 5 Systolic arterial pressure (mean \pm SD) measurements were similar in both groups.

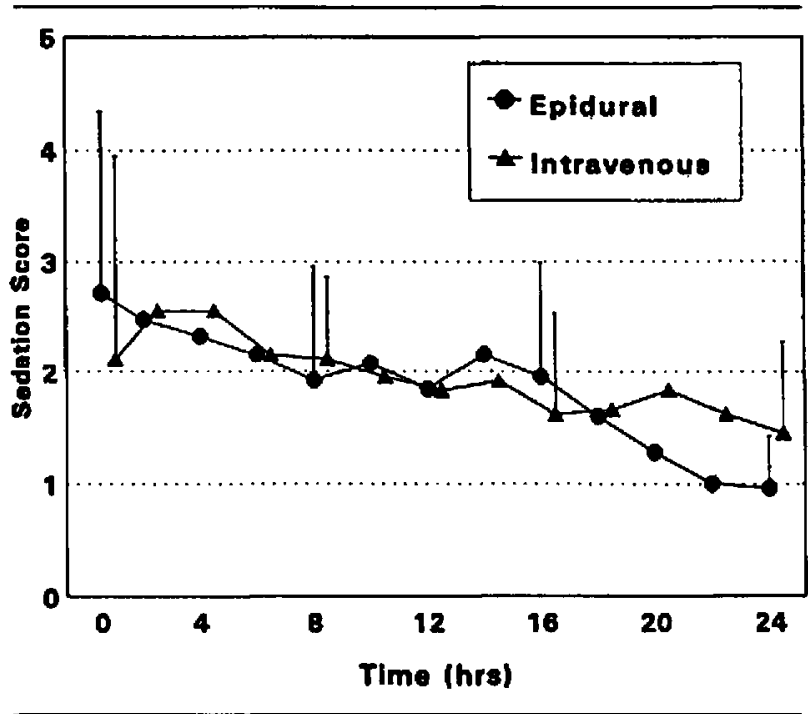

FIGURE 6 Sedation scores were similar in the two groups (mean \pm SD).

\section{Side effects}

There was no difference in the incidence of pruritus or nausea and vomiting between the two groups (Table III). Sedation scores (Figure 6) diminished with time $(P<$ 0.001 ), but were similar in the two groups.

\section{Morbidity and outcome}

Complications such as atelectasis, pneumonia, and persistent air leak occurred with equal frequency in both groups (Table IV). One patient in each group developed respiratory failure later beyond the study period, and one patient in the epidural group died later in hospital from 
TABLE IV Morbidity and mortality - there was no difference between the two groups

\begin{tabular}{lll}
\hline & Epidural & Intravenous \\
\hline Atelectasis $(n)$ & 1 & 4 \\
Pneumonia $(n)$ & 0 & 3 \\
Persistent air leak $(n)$ & 1 & 3 \\
Respiratory failure $(n)$ & 1 & 1 \\
Death $(n)$ & 1 & 0 \\
Hospital stay (Days, mean \pm SD) & $10.7 \pm 3.6$ & $10.8 \pm 4.2$ \\
\hline
\end{tabular}

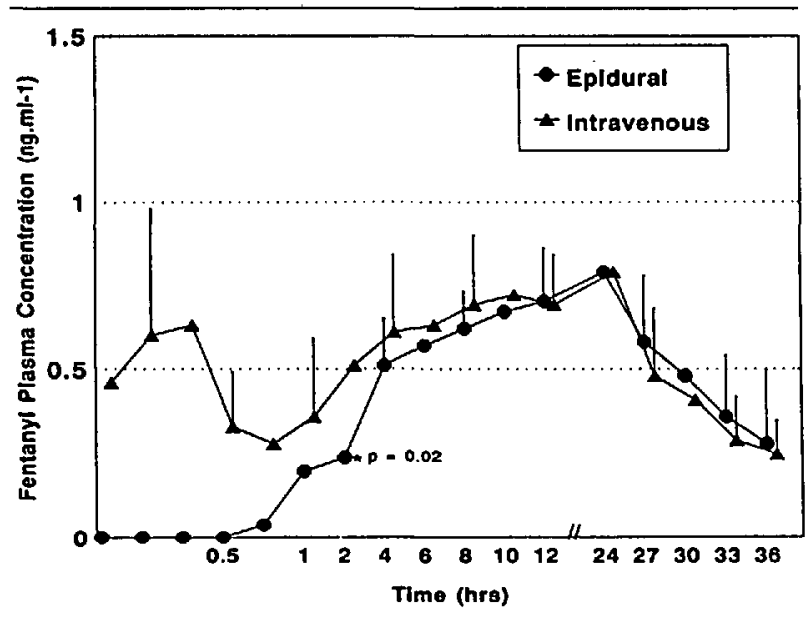

FIGURE 7 Plasma concentration versus time profile - fentanyl was not detectable in the plasma in the epidural group before two hours, its plasma concentration was lower at two hours $(P=0.002)$, and plasma concentrations (mean $\pm \mathrm{SD}$ ) were similar in the two groups thereafter.

causes unrelated to the study. The duration of hospital stay was the same in the two groups.

\section{Pharmacokinetics}

The plasma concentration profiles of fentanyl measured during the study are shown in Figure 7. In the epidural group, fentanyl was detectable in the plasma of only two patients before two hours, and the plasma concentration up to two hours was less in the epidural group $(P<$ 0.002 ). At four hours and thereafter, there was no difference in plasma concentrations between the two groups.

The elimination half-life $\left(t_{1 / 2} 8.9 \pm 4.1 \mathrm{hr}\right.$ epidural, $8.6 \pm 3.3 \mathrm{hr}$ intravenous) was determined from the slope of the concentration-time curve by linear regression procedure fitted to the terminal data points after infusion was discontinued. The apparent epidural and intravenous clearance $(\mathrm{Cl})$ calculated from the ratio of infusion rate to plasma concentration at $24 \mathrm{hr}$ were equivalent $(22.05$ \pm 5.47 and $22.27 \pm 7.11 \mathrm{ml} \cdot \mathrm{min}^{-1} \cdot \mathrm{kg}^{-1}$ respectively).

\section{Discussion}

Many reports have documented the efficacy of epidural fentanyl infusions for analgesia after surgery or trauma, ${ }^{5-7,11,12,15-17,23-26}$ but there are conflicting reports of the relative efficacy of the intravenous and epidural routes of administration. In this study we used a standard dosage regimen of fentanyl by both routes, and PCA morphine supplementation to allow patients in both groups to titrate themselves to a similar level for analgesia; differences in PCA dosage should then be an indication of any difference in analgesic efficacy between the routes. Analgesia was superior in the epidural group in patients who did not have respiratory depression treated with naloxone, while there was no difference in PCA supplementation, respiratory effects, or side effects.

The infusion rate of $1 \mu \mathrm{g} \cdot \mathrm{kg}^{-1} \cdot \mathrm{hr}^{-1}$ fentanyl was derived from a review of 40 consecutive patients after thoracotomy in our institution. Gourlay ${ }^{20}$ reported a mean requirement of $0.73 \mu \mathrm{g} \cdot \mathrm{kg}^{-1} \cdot \mathrm{hr}^{-1}$ for effective analgesia with intravenous fentanyl following major abdominal surgery.

\section{Analgesia}

At one hour after surgery, many patients were insufficiently cooperative to assess their pain reliably by VAS. In the groups as a whole, there were no differences in VAS or PCA morphine supplementation whether the fentanyl was used by epidural or intravenous infusion, except at two hours when the scores in the epidural group were lower $(P<0.05)$. Before four hours, the epidural patients had lower plasma fentanyl concentrations, less than those reported to be necessary for analgesia with intravenous PCA fentanyl. ${ }^{20}$ Analgesia was therefore mediated mainly by a spinal mechanism in the early hours of the infusion.

Analgesia was adversely affected by the small dose of naloxone received by those patients with $\mathrm{CO}_{2}$ retention, and in patients who did not receive naloxone the analgesia was better in the epidural group than in the intravenous group despite having similar plasma fentanyl concentrations. This also suggests a spinal site of action of the epidural fentanyl, and the effect of naloxone in removing this advantage suggests that it too is acting at a spinal level.

Sandler ${ }^{16}$ used the same variable dose regimen both epidurally (lumbar catheter) and intravenously after thoracotomy, and found equivalent analgesia with the two routes although the infusion rate of fentanyl was higher in the epidural group; as a result of small sample size, the power of that study to detect significant differences in pain score was low (power $=0.57$, cf 0.93 in our study). Grant ${ }^{25}$ reported similar analgesic efficacy but with lower lumbar epidural dosage needed for comparable analgesia than with intravenous injection, again in pa- 
tients after thoracotomy but using a patient-controlled dosing technique. Guinard ${ }^{24}$ found that similar intravenous and lumbar epidural fentanyl infusions were required to produce comparable analgesia after thoracotomy, in a randomized but small and non-blinded study.

\section{Respiratory function}

Since all patients required intravenous morphine in addition to the fentanyl, the respiratory and other effects observed were the result of both drugs. Mild derangement of respiratory pattern was observed in both groups as in other studies in which continuous respiratory monitoring with inductive plethysmography was used. ${ }^{12,16} \mathrm{De}-$ pression of respiratory drive after fentanyl bolus ${ }^{5-7}$ or infusion $^{6,8}$ has been reported using intermittent measurements of respiratory rate, end-tidal $\mathrm{CO}_{2}$, or $\mathrm{CO}_{2}$ response tests. Our study design would tend to limit the upper $\mathrm{PaCO}_{2}$ measurements (and perhaps affect other indices of respiratory centre function) because of naloxone administration above a threshold of $50 \mathrm{mmHg}$; naloxone requirements were similar in both groups, suggesting similar respiratory depression.

\section{Pharmacokinetics}

Fentanyl was detectable in the plasma of only two patients in the epidural group until two hours, and the plasma concentration at two hours was significantly less in the epidural group $(P<0.002)$. The visual analogue scores at this time were lower than in the intravenous group, indicating faster onset and greater analgesic activity with epidural injection. Gourlay ${ }^{13}$ reported more rapid penetration of fentanyl across the dura after lumbar epidural than intravenous bolus injection. After intravenous injection of fentanyl, because of high pulmonary first pass uptake $^{27}$ and rapid distribution in the body, a fast decline in plasma concentration was observed during the first $15 \mathrm{~min}$, and those observations are consistent with our finding of greater efficacy of the epidurally-administered drug two hours after injection.

Similar plasma concentration profiles were observed after four hours with both routes after a bolus and infusion, indicating that a distribution equilibrium was achieved in the body by that time. The pharmacokinetic variables derived from our data are similar to those of Shafer ${ }^{28}$ obtained after intravenous infusion in patients undergoing surgery.

\section{Clinical application}

This study has demonstrated an advantage to the lumbar epidural route compared with intravenous fentanyl infusion for post-thoracotomy analgesia. This advantage was not apparent in smaller studies which lacked adequate power for detection of differences in efficacy. ${ }^{16,24}$ While this advantage was lost if naloxone was given to treat respiratory depression, the majority of patients $(72 \%)$ did not require naloxone and would benefit from the epidural route. Our threshold for defining respiratory depression may be considered by some to be too strict, and with a more liberal policy fewer patients would require naloxone and perhaps benefit from better analgesia.

\section{Conclusion}

This study demonstrates superior analgesia with the lumbar epidural than intravenous infusion of fentanyl at the same dosage regimen for post-thoracotomy pain control, unless naloxone was required to treat respiratory depression. Respiratory depression was mild in most patients, the recovery of pulmonary function was the same, and side effects and postoperative morbidity were unaffected by the route of fentanyl administration. These results support the use of the more invasive lumbar epidural technique for pain management of these patients.

\section{Acknowledgements}

This study was supported by grants from Health and Welfare (Canada), the Ontario Thoracic Society, and Janssen Pharmaceuticals. We were fortunate to have the cooperation of other members of the Department of Anaesthesia, and of Drs. R. Belanger, A. Crepeau, and K. Reid, Department of Thoracic Surgery, whose patients were the subjects of the study. Bard (Canada) provided a PCA pump for the study, and the nursing staff of the recovery room provided invaluable assistance with data collection. Sylvie Paquette assisted with preparation of the manuscript, and Eric Ormsby with statistical advice.

\section{References}

1 Gustafsson LL, Schildt B, Jacobsen $K$. Adverse effects of extradural and intrathecal opiates: report of a nationwide survey in Sweden. Br J Anaesth 1982; 54: 479-86.

2 Stenseth R, Sellevold $O$, Breivik $H$. Epidural morphine for postoperative pain: experience with 1085 patients. Acta Anaesthesiol Scand 1985; 29: 148-56.

3 Shulman M, Sandler AN, Bradley JW, Young PS, Brebner $J$. Postthoracotomy pain and pulmonary function following epidural and systemic morphine. Anesthesiology 1984; 61: 569-75.

4 Asantila R, Rosenberg PH, Scheinin B. Comparison of different methods of postoperative analgesia after thoracotomy. Acta Anaesthesiol Scand 1986; 30: 421-5.

5 Lomessy A, Magnin C, Viale JP, Motin J, Cohen $R$. Clinical advantages of fentanyl given epidurally for postoperative analgesia. Anesthesiology 1984; 61: 466-9.

6 Ahuja Br, Strunin L. Respiratory effects of epidural fentanyl. Anaesthesia 1985; 40: 949-55.

7 Negre I, Gueneron JP, Ecoffey $C$, et al. Ventilatory re- 
sponse to carbon dioxide after intramuscular and epidural fentanyl. Anesth Analg 1987; 66: 707-10.

8 Renaud B, Brichant JF, Clergue F, Chauvin M, Levron $J C$, Viars $P$. Ventilatory effects of continuous epidural infusion of fentanyl. Anesth Analg 1988; 67: 971-5.

9 Sandler AN, Chovaz P, Whiting W. Respiratory depression following epidural morphine: a clinical study. Can Anaesth Soc J 1986; 33: 542-9.

10 Baxter AD, Samson B, Penning J, Doran R, Dube LM. Prevention of epidural morphine-induced respiratory depression with intravenous nalbuphine infusion in postthoracotomy patients. Can J Anaesth 1989; 36: 503-9.

11 Bailey $P W$, Smith BE. Continuous epidural infusion of fentanyl for postoperative analgesia. Anaesthesia 1980; 35: 1002-6.

12 Badner NH, Sandler AN, Koren G, Lawson SL, Klein J, Einarson $T R$. Lumbar epidural fentanyl infusions for postthoracotomy patients: analgesic, respiratory, and pharmacokinetic effects. J Cardiothorac Anesth 1990; 4: 543-51.

13 Gourlay GK, Murphy TM, Plummer JL, Kowalski SR, Cherry DA, Cousins MJ. Pharmacokinetics of fentanyl in lumbar and cervical CSF following lumbar epidural and intravenous administration. Pain 1989; 38: 253-9.

14 Gourlay GK, Cherry DA, Plummer JL, Armstrong PJ, Cousins MJ. The influence of drug polarity on the absorption of opioid drugs into CSF and subsequent cephalad migration following lumbar epidural administration: application to morphine and pethidine. Pain 1987; 31: 297-305.

15 Loper KA, Ready LB, Downey $M$, et al. Epidural and intravenous fentanyl infusions are clinically equivalent after knee surgery. Anesth Analg 1990; 70: 72-5.

16 Sandler AN, Stringer D, Panos $L$, et al. A randomised, double-blind comparison of lumbar epidural and intravenous fentanyl infusions for postthoracotomy pain relief. Anesthesiology 1992; 77: 626-34.

17 Salomäki TE, Laitinen JO, Nuutinen LS. A randomized double-blind comparison of epidural versus intravenous fentanyl infusion for analgesia after thoracotomy. Anesthesiology $1991 ; 75$ : 790-5.

18 Nimmo WS, Todd JG. Fentanyl by constant rate iv infusion for postoperative analgesia. $\mathrm{Br} \mathrm{J}$ Anaesth 1985; 57 : 250-4.

19 Duthie DJR, McLaren AD, Nimmo WS. Pharmacokinetics of fentanyl during constant iv infusion for the relief of pain after surgery. $\mathrm{Br} \mathrm{J}$ Anaesth 1986; 58: 950-6.

20 Gourlay GK, Kowalski SR, Plummer $J$, Cousins MJ, Armstrong PJ. Fentanyl blood concentration-analgesic response relationship in the treatment of postoperative pain. Anesth Analg 1988; 67: 329-37.

21 Baxter AD, Laganière S, Samson B, McGilveray IJ, Hull $K$. A dose-response study of nalbuphine for post-thoracotomy epidural analgesia. Can J Anaesth 1991; 38: 175-82.

22 Laganière $S$, Goernert L, Gallicano $K$, Otson $R$.
Improved extraction sensitivity, specificity, and stability for measuring fentanyl in plasma by gas chromatography with nitrogen detection (Letter). Clin Chem 1993;

39: 2206-7.

23 Glass PSA, Estok P, Ginsberg B, Goldberg JS, Sladen $R N$. Use of patient-controlled analgesia to compare the efficacy of epidural to intravenous fentanyl administration. Anesth Analg 1992; 74: 345-51.

24 Guinard JP, Mavrocordatos P, Chiolero R, Carpenter RL. A randomized comparison of intravenous versus lumbar and thoracic epidural fentanyl for analgesia after thoracotomy. Anesthesiology 1992; 77: 1108-15.

25 Grant RP, Dolman JF, Harper JA, et al. Patientcontrolled lumbar epidural fentanyl compared with patientcontrolled intravenous fentanyl for post-thoracotomy pain. Can J Anaesth 1992; 39: 214-9.

26 Mackersie RC, Karagianes TG, Hoyt DB, Davis JW. Prospective evaluation of epidural and intravenous administration of fentanyl for pain control and restoration of ventilatory function following multiple rib fractures. J Trauma 1991; 31: 443-51.

27 Roerig DL, Kotrly KJ, Vucins EJ, Ahlf SB, Dawson CA, Kampine JP. First pass uptake of fentanyl, meperidine, and morphine in the human lung. Anesthesiology 1987; 67: 466-72.

28 Shafer SL, Varvel JR, Aziz N, Scott JC. Pharmacokinetics of fentanyl administered by computer-controlled infusion pump. Anesthesiology 1990; 73: 1091-102. 